CEEAPIA

Centro de Estudos de

Economia Aplicada do Atlântico

WORKING PAPER SERIES

CEEApIA WP No. 08/2008

Real Options Valuation: an Application to the Portuguese Real Estate Market

Carla Oliveira

Gualter Couto

Pedro Pimentel

June 2008

Universidade dos Açores

Universidade da Madeira 


\title{
Real Options Valuation: an Application to the Portuguese Real Estate Market
}

\author{
Carla Oliveira \\ Universidade dos Açores (DEG) \\ Gualter Couto \\ Universidade dos Açores (DEG) \\ e CEEApIA \\ Pedro Pimentel \\ Universidade dos Açores (DEG) \\ e CEEApIA
}

Working Paper n. ${ }^{\circ}$ 08/2008

Junho de 2008 
CEEAplA Working Paper n. ${ }^{\circ}$ 08/2008

Junho de 2008

\section{RESUMOIABSTRACT}

\section{Real Options Valuation: an Application to the Portuguese Real Estate Market}

The contribution of real options analysis on the valuation of Portuguese undeveloped building sites is significant on the decision making regarding the apartment-buildings construction. Using the options model developed by Quigg (1993), and including the necessary readjustments for the Portuguese market, it was found that the scale price elasticity parameter and construction expenditures' elasticity of scale parameter had a strong impact on building sites' values. The empirical analysis revealed that the option to defer adds value to undeveloped building sites' valuations. This fact cannot be ignored when deciding upon an investment's implementation.

Keywords: Real options, real estate, uncertainty, defer, optimal timing.

JEL Classification: D81; D92.

Carla Oliveira

Departamento de Economia e Gestão

Universidade dos Açores

Rua da Mãe de Deus, 58

9501-801 Ponta Delgada

Gualter Couto

Departamento de Economia e Gestão

Universidade dos Açores

Rua da Mãe de Deus, 58

9501-801 Ponta Delgada

Pedro Pimentel

Departamento de Economia e Gestão

Universidade dos Açores

Rua da Mãe de Deus, 58

9501-801 Ponta Delgada 


\title{
REAL OPTIONS VALUATION: AN APPLICATION TO THE PORTUGUESE REAL \\ ESTATE MARKET
}

\author{
Carla Oliveira \\ University of the Azores, \\ Business and Economics Department \\ R. Mãe de Deus, 9500 Ponta Delgada, Portugal, carla.oliveira@nsl.pt \\ Gualter Couto \\ University of the Azores \\ Business and Economics Department, CEEAplA, \\ R. Mãe de Deus, 9500 Ponta Delgada, Portugal, gcouto@notes.uac.pt \\ Pedro Pimentel \\ University of the Azores, \\ Business and Economics Department, CEEAplA \\ R. Mãe de Deus, 9500 Ponta Delgada, Portugal, ppimentel@notes.uac.pt
}

This draft: June, 2008

\begin{abstract}
The contribution of real options analysis on the valuation of Portuguese undeveloped building sites is significant on the decision making regarding the apartment-buildings construction. Using the options model developed by Quigg (1993), and including the necessary readjustments for the Portuguese market, it was found that the scale price elasticity parameter and construction expenditures' elasticity of scale parameter had a strong impact on building sites’ values. The empirical analysis revealed that the option to defer adds value to undeveloped building sites' valuations. This fact cannot be ignored when deciding upon an investment's implementation.
\end{abstract}

Keywords: Real options, real estate, uncertainty, defer, optimal timing.

JEL Classification: D81; D92. 


\section{Introduction}

Modifying the option's model developed by Quigg (1993) for the Portuguese market, we will test parameters that have more impact, positive or negative, on building sites' values. This analysis will also test whether the option to defer adds value to undeveloped building sites, since this is an important aspect to consider when deciding on an investment's implementation.

Contrary to the traditional investment's valuation models, the real options valuation methodology provides the possibility to grasp the options' value within the assets, witch benefits from the flexibility of companies’ strategic management (Quigg, 1993; Brennan and Schwartz, 1985; Majd and Pindyck, 1987; Dixit and Pindyck, 1994; Trigeorgis, 1996 and Luehrman, 1998).

Investments that have been found to disclose a bigger incidence of real options analysis include natural resources investments, building sites' development, research and development, and new entrepreneurial ventures. However, the application of real options analysis to real estate market throughout the years has revealed to be an appealing subject. In this sense, Geltner (1989) created a financial options' model used to evaluate the main features of urban building sites.

Titman (1985) was one of the first researchers to develop a theoretical option model to estimate building site’s value. The intuition of his model essentially reflects that "an undeveloped lot can be viewed as a call option over one in many different buildings at the exercise price that is equal to the corresponding construction expenditures". The decision to invest, or not, can be understood as the relationship between the opportunity cost of keeping the building site undeveloped compared to the expected gain of constructing an appropriate building in the future. If the construction is carried out instantaneously, the opportunity cost of deferring the project will increase, thus decreasing the project's value and increasing the investment incentive (MacDonald and Siegel, 1986). 
In 1991, Williams (1991) developed a Black and Scholes (1973) type model and evaluated building sites as an option with stochastic construction costs, calculating the optimal timing to construct or abandon the property. These optimal investment rules can also be used to determine projects with sequential investments and maximum construction rates, Majd and Pindyck (1994).

The uncertainty over the buildings' future values is often indicated as the main cause for building sites remaining undeveloped for long periods of time. As the volatility of real estate prices increases, ceteris paribus, the option's value also increases (Quigg, 1992). Thus, the option's analysis can explain the existence of many undeveloped properties, even when these prove to be opportunities to construct rentable buildings (Quigg, 1993).

Quigg (1993) enlarged the models used by Titman (1985) and Williams (1991), presenting a study that provides empirical countenances to the developed option valuation, identifying that "the market prices reflect an option premium related to the investment deferring, with an expected value of 6\%”. Bulan, Mayer and Somerville (2002) studied 1214 condominiums under construction in Vancouver, Canada, between 1979 and 1998, identifying that uncertainty delays the investment.

Taking into account that the right to choose the time and construction density has value, and that uncertainty increases the option's value, Capozza and Li (1994) argued that the option's value includes an “irreversibility premium” and an "intensity premium for applied capital” and also defined the option's value as the "net increase premium". Yanxiang and Cannaday (2004) reinforced stating that the option over the property's development gives the owner the right to choose the optimal timing, dimension and style to develop, subject to the legal restrictions. Thus, the option's exercise will occur when the developed property's value exceeds its development costs, which includes building site's acquisition and construction expenditures.

Quigg's (1993) work was the first to include empirical forecasting in the real options model, using a large sample of real estate transactions prices. Capozza and Schwann (1990) tested the valuation model of 
urban assets and focused their analysis on the empirical dimensions of risk effects in urban building sites' prices.

Regarding the investment's uncertainty analysis, Holland, Ott and Riddiough (2000) have empirically discovered a significant negative relationship of short term between the total uncertainty and the investment rate for most of the commercial real estate styles. In 2000, Sivitanidou and Sivitanides (2000) have demonstrated the contribution of the new constructions over the volatility for the underlying demand movements.

Sing and Patel (2001) have shown irreversibility on the building sites' market in the United Kingdom. These researchers have analyzed investment decisions in different stages of the building site development process, facing different sources of uncertainty. Through time series of economic data and specific data on several crossed sectors, Yamazaki (2001) created empirical tests for the real options analysis model using 4.368 building sites' prices in Tokyo, over a period of fifteen years (1985-2000). The empirical results found by Yanxiang and Cannaday (2004) indicated that, on average, 32\% of the free building sites market value corresponds to the option to defer. The value of the option to defer increased relatively to the lot size and uncertainty. Yao and Pretorius (2004) evaluated the housing market of Hong Kong, evidencing that there are several possible uses for building sites acquired through leasing systems, in which is included a premium paid to the local Government State.

This study aims the valuation of undeveloped building sites for constructing new apartment-buildings in Portugal, using a real options analysis framework, based on Quigg's (1993) model. This issue is particularly interesting not only for the academic mainstream, regarding the development of new valuation models with practical applicability, but also for Portuguese real-estate promotional companies which can make use of a new instrument of analysis that will allow them to interpret market price evolution and to determine, in a more realistic way, their projects' value. 
This paper is divided as follows: Introduction; Valuation Methodology; Empirical Results and Conclusion.

\section{Valuation Methodology}

We chose to test the option to defer an investment's project in the Portuguese real estate market, using a real options' valuation model developed by Quigg (1993). This model is one of the pioneers used in the empirical analysis associated with the valuation of investments incorporating the option to defer the development of undeveloped building sites, using real options analysis.

In Quigg's (1993) model it's stated that building sites, or allotments, are associated with a determined value that evidences a construction's option. The value of this option depends on the market's awareness. At any moment in time, the value of the option to defer increases as the real estate project's price volatility increases, as well as the construction's expenditures increases. An option of this type constitutes an instrument that, by definition, cannot assume a value less than zero. Hence, the option's value will have to be implicit in the building sites' valuation and tends to be lower if the investors incur higher costs associated with the investment delay.

According to Quigg (1993), the representative function of construction expenditures is given by:

$$
\mathrm{X}=f+q^{\gamma} x_{1}
$$

Where:

$$
\begin{aligned}
& f \text { - fixed costs; } \\
& q \text { - square meters of the building construction; } \\
& \gamma \text { - construction expenditures' elasticity of scale, and; } \\
& x_{1} \text { - construction expenditures per square meter. }
\end{aligned}
$$

The price, $P$, of the underlying asset (the building) is assumed to be observable, and given by: 


$$
P=q^{\phi} \varepsilon x_{2}
$$

Where:

$\varepsilon$ - function of other building sites’ attributes;

$\phi$ - price elasticity of scale; and

$x_{2}$ - price in euros per square meter of the new apartment-buildings.

The price function used in the empirical study differs from Quigg's (1993) base model, since it considers directly the function of the apartment-buildings' price in euros per square meter. This kind of price function is very close to the function defined in the work of Williams (1991).

Thus, the undeveloped building sites' value, with the embedded option to defer, is given by:

$$
V(P, X)=X\left(A z^{j}+k\right)
$$

where:

$$
\begin{gathered}
A=\left(z^{*}-1-k\right)\left(z^{*}\right)^{-j} ; \\
z^{*}=\frac{j(1+k)}{(j-1)} ; \\
k=\frac{\beta z}{\left(i-v_{x}\right)} ; \\
j=\omega^{-2}\left(0,5 \omega^{2}+v_{x}-v_{p}+\left[\omega^{2}\left(0,25 \omega^{2}-v_{p}-v_{x}+2 i\right)+\left(v_{x}-v_{p}\right)^{2}\right]^{1 / 2}\right) ;
\end{gathered}
$$

and,

$$
z=P / X
$$

The apartment-building risk adjusted drift parameter, construction expenditures risk adjusted drift parameter, risk free interest rate, variance, and the undeveloped building sites' revenues are correspondently represented by $v_{p}, v_{x}, i, \omega$ and $\beta$. 
Quigg suggests that the intrinsic value is obtained through the determination of the limit of $V(P, X)$ when variance $\omega$ tends to 0 . Thus, we will obtain for the intrinsic value the following functions:

$$
\begin{aligned}
& V^{I}(X, P)=P-X, \quad \text { for } z \geq 1+k \\
& V^{I}(X, P)=\frac{\beta P}{\left(i-v_{x}\right)}, \text { for } z<1+k
\end{aligned}
$$

Quigg (1993) assumes that there is a ratio of construction expenditures regarding building price $z$, that represent the optimal timing for construction. In this case, the ratio $z=P / X$ exceeds $1+k$. Therefore, the owner should construct immediately, otherwise they will keep the building site with the income that it generates. The optimal timing for the construction will be reached when $z$ exceeds $z$.

The value of the option to defer computed by the binomial method will be used in terms of comparative analysis. The adoption of this method implies the definition of the underlying asset's price process, which could increase or decrease in a determined ratio (parameters $u$ and $d$ ), in each period of time.

Knowing that $X$ represents the expenditure associated with the investment's implementation (or exercise price) in each one of the situations, the value of the call option is obtained through:

$$
C_{u}=\max \left(u \cdot S_{0}-X ; 0\right)
$$

and

$$
C_{d}=\max \left(d \cdot S_{0}-X ; 0\right)
$$

The trinomial lattice was initially introduced by Boyle (1986) in real options analysis. This valuation method is very similar to the binomial, where the option is determined through a rollback procedure, such that, in the trinomial case, the underlying asset evolves according to three different states of the world 
instead of two, as in the binomial. Thus, the value of the underlying asset may, in each period of the method, present ascending and descending movements or remain unchanged.

The results obtained by the binomial and trinomial models will be, in the limit, equivalent. However, the results reached by the trinomial model more quickly converge into the option's accurate valuation (Mun, 2003).

\section{Empirical Results}

In real options' analysis, it's possible to assess the value of the manager's capacity to respond to external changes exercising or not the options that are associated with the investment's opportunities. Most decisions on real estate investments are irreversible. Therefore, the optimal timing regarding decision making is of paramount importance. It's our purpose to present the empirical results, regarding the application of the real options analysis to the Portuguese real estate market. The embedded option considered in these investments opportunities is related with the option to defer the construction of apartment-buildings.

The Portuguese real estate sector is extremely risky, dependent on the market conjuncture and on the Government construction policies. Real estate investments tend to be of a long term period (which is related to the building sites own durability). The time and costs associated with the building sites' transactions are normally high; however, the real estate investments' return is generally higher compared to other kinds of investments (Banha, 2000).

The historical data that will be analyzed refers to the period of 2001 to 2005 . These data are segmented by territorial regions, namely, North, Oporto Metropolis, Centre, Lisbon and Tagus Valley, Lisbon Metropolis, Alentejo and Allgarve. Our intention is to apply consistent data to the empirical process. 
In Portugal, the asset of real estate companies does not reflect the true value of building sites, since they are registered at book value, which generally is lower to the market's value at witch the transaction is made. Through the analysis of the apartment-buildings market, we notice a continuous growth in the number of housing between 2000 and 2005. However, from 2002 onward, the increments are successively smaller, indicating a deceleration of the investment in the real estate sector. The regions that contributed the most to this decline were the regions of North, Centre and Lisbon.

Analyzing the main construction indicators for new family houses in the Portuguese territory, including the Autonomous Regions of Azores and Madeira, we find that the average building was composed of two floors and five divisions, with each division having an average area of 18.5 square meters. Our analysis reveals that big cities present, on average, buildings with a larger number of floors. The maximum of which was 10.2 floors, in 2004, in Lisbon.

The trend verified up to 2002 is related to the government incentive policy to construction and acquisition of one's own house. However, after 2002 the end of the home low-cost loaning contributed to the decline of real estate activity in the subsequent years (Ministry of the Public Works, Transports and Habitation - State Secretary of the Habitation, 2004).

In the sample, the total number of new apartment buildings was $34,765,66 \%$ of them were built in the first three years (2001, 2002 and 2003) of the analysed period. Table 1 presents the apartment's transaction prices in Euros per square meter in Portugal given by the banking valuation. This valuation process was created to understand the technical assessment of the properties that the bank will be financing. In the whole sample, the higher values were found in Lisbon Metropolis and the smallest ones in the North region. Between 2001 and 2005, the average transaction price per square meter increased around $15.16 \%$ regarding the apartment-buildings in Portugal's territory.

[Insert Table 1] 
A detailed analysis shows that the regions that contributed the most for the prices' increase between 2001 and 2005 were Alentejo and Allgarve. The touristic region of Allgarve records the second highest transaction prices per square meter.

Using the geographic segmentation of the national annual data, based on location coefficients, we get the construction expenditures per square meter for the apartment-buildings, presented in Table 2 . According to Table 2, in 2005 the region where it was found the highest amount of construction expenditures was the Lisbon metropolis, with 709.19 Euros per square meter, and the smallest was Alentejo, with 354.07 Euros.

\section{[Insert Table 2]}

To compute the value of the option to defer the apartment-buildings construction, the apartment's size in square meters to be used in the real option analysis framework will correspond to the average size in square meters between the years of 2001 and 2005, in each of the considered regions. We assume that there are no fixed construction expenditures such as building site registration or construction permissions, because this study does not consider the ground site acquisition. Thus, $f$ will be zero in Quigg's (1993) adjusted model. The risk free interest rate, $i$, used in the valuation of the option to defer the apartmentbuilding's construction was $4.62 \%$ per year. This risk free interest rate was estimated considering the Treasury Bonds with 10 years to maturity available by Reuters, 1999 to 2005. The construction expenditures' elasticity of scale, $\gamma$, corresponds to the established relationship between the apartmentbuilding's size and construction expenditures. To obtain economies of scale, it is assumed that the value of $\gamma$ varies between 0.9 and 1, as is also assumed in Quigg (1993).

The undeveloped building sites' revenues, $\beta$, corresponds to net cash flows obtained through its alternative use, that is, the agrarian income. This variable assumed a value between $0.8 \%$ and $3 \%$ of the apartment-building value. The scale/price elasticity of the apartment-buildings, $\phi$, is equivalent to the existing relationship between the apartment-building's size and its value. However, once the estimated 
building price reflects the effect of the scale/price elasticity, we assume that the elasticity value is equal to 1. The standard deviation of $X, \sigma_{x}$, is calculated using the natural logarithm of the instantaneous annual variations of the global construction expenditures of the new apartment-building. Through a similar approach, we calculate the standard deviation of $P$ and its variance.

The correlation coefficient between construction expenditures and the apartment-buildings price, $\rho_{x p}$, should be, as much as possible, proximate to one, under the assumption that the profit margin for constructors remain stable. The apartment-building risk adjusted drift parameter will correspond to the risk free interest rate. However, the use of the estimated $v_{p}$, in Quigg's adjusted model (1993) may lead to indeterminate solutions. Thus, its necessary to set a variation bounds for the return rate, using the Williams (1991) inequality, such that, $v_{p}<i \leq 1+v_{p}$. This equation establishes a relationship between the risk free interest rate and the risk-adjusted return. This way, the values obtained for $v_{p}$ will occur between $-0,954 \leq v_{p}<0,046$. Considering that, $v_{x} \geq v_{p}$ (Williams, 1991), the assumed value for $v_{x}$ will be 0,03, for the base scenario of Quigg’s (1993) adjusted model.

Using sensitivity and Tornado analysis on the investment's traditional NPV, and consequently, on the variables that compose it, it is possible to verify the parameters that produce a stronger impact on the building sites' total value. The parameters that show a higher contribution in the total variance of the building site's value are, for decreasing order of sensitivity, the building scale/price elasticity, the construction expenditures' elasticity of scale and the building's price in euros per square meter. The north region contribution in total variance given by the scale/price elasticity is $81.4 \%$, whereas the construction expenditures' elasticity of scale has a negative impact on the traditional NPV of approximately $17 \%$.

Based on historical data between 2001 and 2005 of the new apartment-buildings in Portugal, the common input parameters to all the regions for the base scenario are described in Table 3. In this Table we 
find the values for the fixed costs construction expenditures' elasticity of scale, price elasticity of scale, other building sites attributes, undeveloped building sites revenues, apartment-building risk adjusted drift parameter, construction expenditures risk adjusted drift parameter, and risk free interest rate.

\section{[Insert Table 3]}

For the base scenario, the price function, $P$, defined by, $q^{\phi} x_{2} \varepsilon$, and the construction expenditures' function, identified by the expression, $f+q^{\gamma} x_{1}$, assume the values given in Table 4. For instance, Lisbon metropolis record 3.86 Millions Euros for the apartment-building price with a standard deviation of 20.624\%, when the construction expenditures accounts for 1.73 Millions Euros. As expected, in all regions, the apartment-building prices come considerably superior to the construction expenditures. The expected future cash flows volatility for the price variable presents an average value of $18,43 \%$, with a maximum value of $27,71 \%$ and a minimum of $7,54 \%$. The apartment-buildings price volatility presents an average value of $18,43 \%$, with a maximum value of $27,71 \%$ in the Centre region and a minimum of $7,54 \%$ in Oporto metropolis.

\section{[Insert Table 4]}

In order to obtain the value of the undeveloped building sites with the embedded option to defer, $V(P, X)$, the values for parameters $z, w^{2}, j, k, z^{*}$ and $A$ were computed based on the previous results. The value for each parameter, for each region, is given in Table 5.

\section{[Insert Table 5]}

Through the analysis of variable $z^{*}$, which corresponds to the optimal timing of the investment's implementation, and considering that the optimal timing to construct the apartment-building occurs when $z$ exceeds $z^{*}$, it is possible to conclude that, on the base scenario case, only the regions North and Alentejo present optimal conditions to develop apartment-buildings.

Considering the values for all parameters presented in Table 5, it will be possible to proceed with the computation of $V(P, X)$ stated in Table 6 . The value of the undeveloped building sites with the embedded 
option to defer, $V(P, X)$, when compared with the corresponding intrinsic value of building sites for apartment construction, $V^{I}(X, P)$, demonstrate that the embedded option to defer contributes to rise building site values.

\section{[Insert Table 6]}

According to the results presented in Table 6, it is possible to conclude that the value of the option to defer represents, on average, about $5.43 \%$ of the building sites' total value. The value of the option to defer varies between $0.16 \%$ and $11.92 \%$. The regions with major option's values are Oporto Metropolis, Lisbon and Tagus Valley and Lisbon Metropolis. Therefore, big urban centres, with expected cash flows exposed to major uncertainty, evidence higher option premiums comparatively to the rest of the country. The building site value sensitivity analysis, obtained through Quigg's (1993) adjusted model, contemplates a variation in the construction expenditures' elasticity of scale, $\gamma$, which decreases from 1 to 0.9. Table 7 presents the results for this scenario.

\section{[Insert Table 7]}

According to Table 7, when the construction expenditures' elasticity of scale decreases from 1 to 0.9 , the value of the option to defer increases, due to the reduction on construction's global expenditures. In this scenario, the average value of the option to defer is $12.76 \%$ relative to the building site total value. The lower and upper relative value is $0.15 \%$ in the Centre region and $29.94 \%$ in the North region, correspondingly. However, in the regions of the Centre, Lisbon, Tagus Valley and Lisbon Metropolis, the relative value of the option to defer towards the corresponding building sites total value decreases in relation to the base scenario. This is because the reduction verified in the construction expenditures' elasticity of scale provides variations in different parameters of the model. In the regions mentioned previously, this effect is superior to the impact inducted from variations on the construction expenditures.

The variation that occurred on the construction expenditures' elasticity of scale enables all regions attaining the optimal timing for the development of new apartment-buildings construction. By changing 
the value of the parameter $\beta$, which refers to the undeveloped building site revenue, from the $0.8 \%$ base scenario to $3 \%$, is possible to verify that, as expected, the average value of the option to defer embedded in the building sites' valuation is less than the corresponding value in the base scenario. Assuming the increase in undeveloped building sites revenues, it becomes more attractive to its owners to continue benefiting from these revenues, and thus, delaying the construction. The change made in the value of the parameter $\beta$ triggers a substantial increase in the threshold value for the ratio between construction expenditures and building price, $z^{*}$. In all regions where $z<z^{*}$, the building sites should not be developed.

Considering again the base scenario, and assuming that the coefficient's correlation of the functions $X$ and $P$ are set equal to zero for all the regions, the building site's total values comes substantially superior to that attained in the base scenario. Notice that the current assumed value for the correlation coefficient was also used in Quigg (1993). The total value of the undeveloped building site, intrinsic value and value of the option to defer are presented in Table 8, when the coefficients' correlation of the function $X$ and $P$ are set equal to zero for all the regions.

\section{[Insert Table 8]}

In this last scenario, the average value of the options relative to the building sites' total value, will reach values around $35.15 \%$, with the relative values lying between $19.78 \%$ for the North region and 45.79\% in the Lisbon and Tagus Valley regions.

The valuation framework related to the binomial and trinomial methods are conducted on a valuation context of discrete time, in which the value of the underlying asset (the new apartment-building), evolves throughout time, considering the existence of favourable and unfavourable states of the world. In the following valuation models, two different scenarios were considered, the base scenario and scenario one. The underlying asset values, construction expenditures and uncertainty upon the underlying asset common to both valuation scenarios are given, accordingly, by the apartment-building price $(P)$, construction 
expenditures ( $X$ ) and standard deviation of the apartment-building price ( ${ }^{\sigma_{P}}$ ), displayed in Table 4 . The risk free interest rate is 4.62\%, equivalent to the one used in Quigg's (1993) adjusted model. The difference between the two scenarios relates to the time horizon, which are 5 years for the base scenario and 10 years for scenario one. The number of steps considered for both scenarios corresponds to the number of years of each scenario.

As expected the values obtained by the binomial model using the 1,000 sub-periods are slightly superior to the values obtained when the valuation process contemplates only 1 sub-period, except for the Centre region. The 1,000 sub-periods were selected to proceed with the binomial and trinomial valuation process.

For each region, Table 9 presents the building sites values obtained from different valuation frameworks, including the binomial and trinomial for 5 and 10 years time horizon. The building sites intrinsic value and building sites values computed by Quigg's model are not affected by the time to maturity, because an infinite time horizon is implicitly assumed.

\section{[Insert Table 9]}

For scenario one, where the assumed time horizon is 9 years, it is possible to conclude that the building site total values given by the binomial model, increases in all regions compared to the base scenario. The verified increment in building site total value demonstrates that, in general, the time horizon has a great impact on the real option analysis framework, and on the option to defer, in particular.

Building sites' values given by the trinomial model, and stated in Table 9, are similar to the ones attained by the binomial model, being superior in the case where the time to maturity is higher, in this case 10 years. This behaviour is similar to the one shown in the binomial model results.

In the base scenario, it is verified that the undeveloped building site's total values given by the binomial and trinomial models, are superior in all regions to the corresponding intrinsic values given by 
traditional NPV. As expected, the higher the volatility associated with the cash flows, the higher will be the value of the embedded option to defer and, consequently, the total value of building sites.

The conclusions obtained for scenario one are very similar to the ones for the base scenario. Thus, in scenario one, the building site total values, in presence of the option to defer the construction, are substantially superior to the base scenario. This increment verified in the building site total values will be superior in the regions that withhold a superior volatility, as is the case of Centre, Lisbon, Tagus Valley and Lisbon Metropolis.

It will also be interesting to do a comparative analysis between the building site total values, with the embedded option to defer, given through the application of the binomial and trinomial models, for the base scenario, and the results given by Quigg's (1993) adjusted model. The building sites values computed by Quigg's (1993) adjusted model are less than half the one computed by the binomial and trinomial models. Recalling the building sites values computed by Quigg's adjusted model when the correlation between the price and construction expenditures is set equal to zero given in Table 8, it is possible to observe that, the building site total values are close to the ones computed by the binomial and trinomial models.

\section{Conclusion}

Aiming to find empirical evidence in the Portuguese real estate market, regarding the option to defer embedded in real asset transaction prices, we apply the real options analysis to value undeveloped building sites, using Quigg's (1993) adjusted model, as well as binomial and trinomial valuation frameworks. The study purpose was also to analyze the valuation frameworks' sensibility.

Through the sensitivity and Tornado analysis conducted on the main parameters that compose the traditional NPV for undeveloped building sites, we can conclude that the parameters that produce a more significant impact on the total value of building sites include the scale/price elasticity of the new apartment-buildings and the construction expenditures' elasticity of scale. The building's price in Euros 
per square meter, the dimension in square meter and the construction expenditures in Euros per square meter, change their level of contribution for the traditional NPV variance according to the region. Therefore, the impacts motivated by these parameters are significantly inferior in the traditional analysis.

After analyzing the building site total value, given by Quigg's (1993) adjusted model, we can conclude that, compared to the base scenario, the average value of the option to defer included in the building sites' total value is 5,43\%, bounded between $0,16 \%$ and $11,92 \%$ for the regions of the North and Lisbon Metropolis, accordingly. It is possible to verify that, when a reduction in the construction expenditures' elasticity of scale from 1 to 0,9 is considered, ceteris paribus, the average level of the value of the option to defer increases by $12,76 \%$. However, the verified increase in the option value, in some of the regions under analysis, only reflects the impact's magnitude of the reduction of the construction's expenditures in the building sites' total value Therefore, the ratio, $z=P / X$ for all regions, is always superior to the critical value, $z^{*}$. This parameter reflects the optimal timing to invest, which occurs when the construction expenditures' elasticity of scale, $\gamma$, reaches its minimum value, making the value of the option to defer equal to zero. On the other hand, whenever there is an increase in the undeveloped building site revenues of 3\%, at the most, the value $z$ remains unchanged when compared with the base scenario. Nonetheless, $z^{*}$ increases significantly, which induces to major delays in the decision to construct new apartment-buildings.

The building sites' total value, given by the binomial and trinomial models, is always superior in all the regions, when compared to the values computed by the traditional NPV and Quigg's (1993) adjusted model. In the base scenario, where the time horizon is 5 years, the average value of the option to defer, relative to the respective building sites total value, is around $53 \%$. Thus, this enables us to conclude that the option to defer is sensible to the time horizon considered for the valuation process.

Finally, it is important to point out some possible extensions to be accomplished in the future in this type of real options frameworks, which were not analyzed in the present work. It may be, also, interesting 
to incorporate into Quigg's (1993) adjusted model, a global function of the construction expenditures that considers the initial fixed expenditure $(f)$ incurred with building site registrations, construction license requirements, and construction taxes. The analysis of the construction expenditures' function could be enlarged with the inclusion of collateral effects resultant from the construction's quality and constructions details of the apartment-building. As for the buildings' price function, this could suffer some changes caused by other land attributes, such as the involving green areas, parking and distance to institutions of public utility, leisure or public transportation. The decomposition of the building price function for the new apartments, by size type, could be of higher utility, as well as the subsequent analysis to the optimal size of the building to construct.

\section{References}

Banha, F. (2000). Avaliação de Empresas: O Estado da Arte no Sector Imobiliário. Artigo de Opinião, Gesbanha - Gestão e Contabilidade, S.A..

Black, F., and Scholes, M. (1973). The Pricing of Options and Corporate Liabilities. Journal of Political Economy, 81, May-Jun, 637-659.

Boyle, P. (1986). Option Valuation Using a Three-Jump Process. International Options Journal, 3, 7-12. Brennan, M., and Schwartz, E. (1985). Evaluating Natural Resource Investments. Journal of Business, 58 (2), 135-157.

Bulan, L., Mayer, C. J., and Somerville,T. (2002). Irreversible Investment, Real Options, and Competition: Evidence from Real Estate Development. Working Paper, UBC Commerce Center for Urban Economics and Real Estate.

Capozza, D., and Li, Y. (1994). The Intensity and Timing of Investment: The Case of Land. American Economic Review, 84 (4), 889-904.

Capozza, D., and Schwann, G. (1990). The Value of Risk in Real Estate Markets. Journal of Real Estate Finance and Economics, 3, 117-140.

Dixit, A., and Pindyck, R. (1994). Investment under Uncertainty. New Jersey: Princeton University Press, Princeton.

Geltner, D. (1989). On the Use of the Financial Option Price Model to Value and Explain Vacant Urban Land. AREUEA Journal, 17 (2), 142-158. 
Holland, A., Ott, S., and Riddiough, T. (2000). The Role of Uncertainty in Investment: An Examination of Competing Investment Models Using Commercial Real Estate Data. Real Estate Economics, 28 (1), 3364.

Luehrman, T. (1998). Investment Opportunities as Real Options: Getting Started on the Numbers. Harvard Business Review, 51-67.

MacDonald, R., and Siegel, D. (1986). The Value of Waiting to Invest. The Quartely Journal of Economics, 101 (4), Nov, 707-728.

Majd, S., and Pindyck, R. (1987). Time to Build, Option Value, and Investment Decisions. Journal of Financial Economics, 18 (1), 7-27.

Ministério das Obras Públicas (2004). Transportes e Habitação. Relatório da Secretaria de Estado da Habitação.

Mun, J. (2003). Real Options Analysis Course: Business Cases and Software Applications. New York: Wiley \& Sons.

Quigg, L. U of I’s Laura Quigg (1992). Applies Real Options Concept to Real Estate. ORER Letter, Spring/Summer, 10-13.

Quigg, L. (1993). Empirical Testing of Real Option-Pricing Modules. The Journal of Finance, 48, 621640.

Sing, T. F., and Patel, K. (2001). Evidence of Irreversibility in the UK Property Market. The Quartely Review of Economics and Finance, 41, 313-334.

Sivitanidou, R., and Sivitanides, P. (2000). Does the Theory of Irreversible Investments Help Explain Movements in Office - Commercial Construction?. Real Estate Economics, 28, 623-661.

Titman, S. (1985). Urban Land Prices under Uncertainty. American Economic Review, 75 (3), 505-514.

Trigeorgis, L. (1996). Real Options: Managerial Flexibility and Strategy in Resource Allocation. Cambridge, MA. The MIT Press.

Williams, J. (1991). Real Estate Development as an Option, Journal of Real Estate Finance and Economics, 4, 191-208.

Yamazaki, R. (2001). Empirical Testing of Real Option Pricing Models Using Land Price Index in Japan. Journal of Property Investment \& Finance, 19 (1), 53-72.

Yanxiang, A., and Cannaday, R. (2004). Value of the Option to Develop Residential Land: An Empirical Estimate. Real Estate Review, Winter, 32(4), 60 -65.

Yao, H., and Pretorius, F. (2004). Empirical Testing of Real Options in the Hong Kong Residential Real Estate Market. Working Paper, University of Hong Kong. 
Table 1. Apartment Transaction's Prices in Euros per Square Meter in Portugal Between 2001 and 2005.

\begin{tabular}{lrrrrr}
\hline Regions & $\mathbf{2 0 0 1}$ & $\mathbf{2 0 0 2}$ & $\mathbf{2 0 0 3}$ & $\mathbf{2 0 0 4}$ & $\mathbf{2 0 0 5}$ \\
\hline North & 977.70 & $1,008.25$ & $1,059.37$ & $1,093.33$ & $1,110.58$ \\
Oporto Metropolis & $1,105.00$ & $1,148.75$ & $1,208.24$ & $1,241.96$ & $1,248.32$ \\
Centre & 982.30 & $1,032.00$ & $1,099.82$ & $1,145.28$ & $1,182.67$ \\
Lisbon and Tagus Valley & $1,262.00$ & $1,264.25$ & $1,382.98$ & $1,426.60$ & $1,439.74$ \\
Lisbon Metropolis & $1,398.50$ & $1,375.25$ & $1,536.35$ & $1,573.07$ & $1,577.96$ \\
Alentejo & $1,000.00$ & $1,039.75$ & $1,121.02$ & $1,214.35$ & $1,252.70$ \\
Allgarve & $1,167.50$ & $1,247.25$ & $1,388.77$ & $1,462.45$ & $1,487.64$ \\
\hline Average & $1,167.50$ & $1,247.25$ & $1,388.77$ & $1,462.45$ & $1,487.64$
\end{tabular}

Font: INE. IABH. DGEP. 2001 to 2005.

Table 2. Apartment Transaction's Prices in Euros per Square Meter by Regions.

\begin{tabular}{lrrrrr}
\hline Regions & $\mathbf{2 0 0 1}$ & $\mathbf{2 0 0 2}$ & $\mathbf{2 0 0 3}$ & $\mathbf{2 0 0 4}$ & $\mathbf{2 0 0 5}$ \\
\hline North & 977.70 & $1,008.25$ & $1,059.37$ & $1,093.33$ & $1,110.58$ \\
Oporto Metropolis & $1,105.00$ & $1,148.75$ & $1,208.24$ & $1,241.96$ & $1,248.32$ \\
Centre & 982.30 & $1,032.00$ & $1,099.82$ & $1,145.28$ & $1,182.67$ \\
Lisbon and Tagus Valley & $1,262.00$ & $1,264.25$ & $1,382.98$ & $1,426.60$ & $1,439.74$ \\
Lisbon Metropolis & $1,398.50$ & $1,375.25$ & $1,536.35$ & $1,573.07$ & $1,577.96$ \\
Alentejo & $1,000.00$ & $1,039.75$ & $1,121.02$ & $1,214.35$ & $1,252.70$ \\
Allgarve & $1,167.50$ & $1,247.25$ & $1,388.77$ & $1,462.45$ & $1,487.64$
\end{tabular}

Font: INE, IABH, DGEP, 2001 to 2005.

Table 3. Common Parameters that Compose the Base Scenario.

\begin{tabular}{lllllllll} 
Variables & $f$ & $\gamma$ & $\phi$ & $\varepsilon$ & $\beta$ & $v_{x}$ & $v_{p}$ & $i$ \\
\hline Value & 0 & 1 & 1 & 1 & $0.80 \%$ & 0.03 & 0.03 & $4.62 \%$ \\
\hline
\end{tabular}


Table 4. Apartment-Building Prices ( $P$ ), Construction Expenditures ( $X$ ) and Standard Deviation of the Apartment-Building Prices $\left(\sigma_{P}\right)$, for the Base Scenario by Regions.

\begin{tabular}{lcrc}
\hline Regions & $P$ & $X$ & \multicolumn{1}{c}{$\sigma_{P}$} \\
\hline North & $2,616,339.32$ & $902,210.93$ & $9,643 \%$ \\
Oporto Metropolis & $3,735,995.18$ & $1,792,144.60$ & $7,541 \%$ \\
Centre & $1,891,658.49$ & $570,032.14$ & $27,707 \%$ \\
Lisbon and TV & $2,771,009.80$ & $1,283,276.78$ & $21,404 \%$ \\
Lisbon Metropolis & $3,859,292.06$ & $1,734,511.17$ & $20,624 \%$ \\
Alentejo & $1,454,470.99$ & $411,099.31$ & $20,610 \%$ \\
Allgarve & $2,209,961.17$ & $905,705.06$ & $21,453 \%$ \\
\hline
\end{tabular}

Table 5. Values of $z, w^{2}, j, k, z^{*}$ and $A$ for the initial moment (0), by Regions.

\begin{tabular}{lllllll}
\hline Regions & $z$ & $w^{2}$ & $j$ & $k$ & $z^{*}$ & $A$ \\
\hline North & 2.900 & 0.001 & 6.861 & 1.432 & 2.847 & 0.000 \\
Oporto Metropolis & 2.085 & 0.001 & 7.071 & 1.029 & 2.364 & 0.001 \\
Centre & 3.319 & 0.006 & 2.956 & 1.639 & 3.988 & 0.023 \\
Lisbon and TV & 2.159 & 0.001 & 5.315 & 1.066 & 2.545 & 0.003 \\
Lisbon Metropolis & 2.225 & 0.003 & 3.817 & 1.099 & 2.844 & 0.014 \\
Alentejo & 3.538 & 0.001 & 6.275 & 1.747 & 3.268 & 0.000 \\
Allgarve & 2.440 & 0.001 & 5.333 & 1.205 & 2.714 & 0.002 \\
\hline
\end{tabular}

Table 6. Values of $V(P, X), V^{I}(X, P)$ and Option to Defer in Euros by Regions.

\begin{tabular}{lrrr}
\hline Regions & $V(P, X)$ & $V^{I}(X, P)$ & Option Value \\
\hline North & $1.716 .807,23$ & $1.714 .128,38$ & $2.678,85$ \\
Oporto Metropolis & $2.091 .352,88$ & $1.943 .850,57$ & $147.502,31$ \\
Centre & $1.380 .911,06$ & $1.321 .626,35$ & $59.284,71$ \\
Lisbon and TV & $1.624 .855,63$ & $1.487 .733,01$ & $137.122,62$ \\
Lisbon Metropolis & $2.412 .272,80$ & $2.124 .780,89$ & $287.491,91$ \\
Alentejo & $1.070 .627,92$ & $1.043 .371,68$ & $27.256,24$ \\
Allgarve & $1.352 .731,58$ & $1.304 .256,11$ & $48.475,47$ \\
\hline
\end{tabular}


Table 7. Values of $V(P, X), V^{I}(X, P)$ and Option to Defer in Euros by Regions, when $\gamma=0,9$.

\begin{tabular}{lrcr}
\hline Regions & $V(P, X)$ & $V^{I}(X, P)$ & Option Value \\
\hline North & $3.142 .190,37$ & $2.201 .295,67$ & $940.894,70$ \\
Oporto Metropolis & $3.529 .701,10$ & $2.931 .052,42$ & $598.648,68$ \\
Centre & $1.621 .577,75$ & $1.619 .073,71$ & $2.504,04$ \\
Lisbon and TV & $2.291 .266,79$ & $2.168 .609,84$ & $122.656,95$ \\
Lisbon Metropolis & $3.080 .251,92$ & $3.064 .349,31$ & $15.902,61$ \\
Alentejo & $1.750 .177,48$ & $1.251 .487,38$ & $498.690,10$ \\
Allgarve & $1.925 .953,01$ & $1.773 .648,15$ & $152.304,87$ \\
\hline
\end{tabular}

Table 8. Values of $V(P, X), V^{I}(X, P)$ and Option to Defer in Euros by Regions, when $\rho=0$.

\begin{tabular}{lccr}
\hline Regions & $V(P, X)$ & $V^{I}(X, P)$ & Option Value \\
\hline North & $2.136 .909,20$ & $1.714 .128,38$ & $422.780,81$ \\
Oporto Metropolis & $2.715 .562,23$ & $1.943 .850,57$ & $771.711,66$ \\
Centre & $2.130 .106,21$ & $1.321 .626,35$ & $808.479,86$ \\
Lisbon and TV & $2.739 .882,70$ & $1.487 .733,01$ & $1.252 .149,68$ \\
Lisbon Metropolis & $3.735 .639,05$ & $2.124 .780,89$ & $1.610 .858,16$ \\
Alentejo & $1.480 .175,44$ & $1.043 .371,68$ & $436.803,76$ \\
Allgarve & $2.231 .903,46$ & $1.304 .256,11$ & $927.647,35$ \\
\hline
\end{tabular}

Table 9. Summary of the Building Sites Values for the Different Methodologies.

\begin{tabular}{|c|c|c|c|c|c|c|}
\hline \multirow{2}{*}{ Regions } & \multirow{2}{*}{$V^{I}(X, P)$} & \multirow{2}{*}{$V(P, X)$} & \multicolumn{2}{|c|}{ Base Scenario } & \multicolumn{2}{|c|}{ Scenario one } \\
\hline & & & Binomial & Trinomial & Binomial & Trinomial \\
\hline North & $1.714 .128,39$ & $1.716 .807,23$ & $3.614 .347,29$ & $3.614 .347,29$ & $3.762 .054,69$ & $3.762 .054,69$ \\
\hline Oporto & $1.943 .850,57$ & 2.091.352,88 & 4.257.349,85 & $4.257 .349,85$ & $4.550 .754,64$ & $4.550 .754,64$ \\
\hline Centre & $1.321 .626,35$ & $1.380 .911,06$ & $2.762 .793,50$ & $2.762 .793,00$ & 2.861.638,57 & 2.861.636,93 \\
\hline $\begin{array}{l}\text { Lisbon and } \\
\text { T. V. }\end{array}$ & $1.487 .733,01$ & 1.624.855,63 & $3.245 .369,80$ & 3.245.360,96 & $3.463 .392,28$ & 3.463.420,35 \\
\hline $\begin{array}{l}\text { Lisbon } \\
\text { Metropolis }\end{array}$ & $2.124 .780,89$ & $2.412 .272,80$ & 4.611.923,26 & 4.611.919,98 & $4.904 .275,43$ & 4.904.271,83 \\
\hline Alentejo & $1.043 .371,68$ & $1.070 .627,92$ & 2.171.585,69 & $2.171 .585,77$ & 2.239.321,63 & 2.239.321,62 \\
\hline Allgarve & $1.304 .256,11$ & $1.352 .731,58$ & 2.797.239,64 & 2.797.239,56 & 2.949.852,39 & $2.949 .855,69$ \\
\hline
\end{tabular}

